\title{
Solution of Dynamic Optimization Problems Constrained by the Fraction Penalty Method
}

\author{
Hartono $^{* 1}$ \\ ${ }^{1}$ Department of Mathematics, Faculty of Science and Technology, Universitas Sanata \\ Dharma Yogyakarta, Indonesia \\ E-mail: yghartono@usd.ac.id ${ }^{* 1}$
}

Submitted: 12 September 2019, revised: 26 February 2020, accepted: 27 February 2020

\begin{abstract}
Abstrak. Artikel ini membahas penerapan metode penalti fraksional untuk menyelesaikan masalah optimisasi dinamis dengan batasan keadaan. Teori utama yang mendukung penggunaan metode ini dijelaskan dalam beberapa teorema dan akibat wajar. Teorema memberikan kondisi yang cukup untuk penerapan metode ini. Oleh karena itu, jika semua kondisi yang disebutkan dalam teorema terpenuhi maka solusi yang dihasilkan akan dikonversi menjadi solusi analitik. Selain itu, ada beberapa contoh untuk mendukung teori tersebut. Simulasi numerik menunjukkan bahwa akurasi metode ini cukup baik. Oleh karena itu, metode ini dapat berperan sebagai metode alternatif untuk menyelesaikan masalah optimisasi dinamis dengan batasan keadaan.
\end{abstract}

Kata kunci: dynamic optimization; state constraints; Pontryagin minimum principle; fractional penalty method

\begin{abstract}
This article discusses the application of fractional penalty method to solve dynamic optimization problem with state constraints. The main theories supporting the use of the method are described in some theorems and corollary. The theorems give sufficient conditions for the application of the method. Therefore, if all conditions mentioned in the theorems are met then the resulted solution will converge to the analytic solution. In addition, there are some examples to support the theory. The numerical simulation shows that the accuracy of the method is quite good. Hence, this method can play a role as an alternative method for solving dynamic optimization problem with state constraints.
\end{abstract}

Keywords: dynamic optimization; state constraints; Pontryagin minimum principle; fractional penalty method

\section{Introduction}

The problem of dynamic optimization or also known as optimal control plays an important role because of many problems such as engineering, industry, social, economic, financial, biological, medical that can be formulated as the problem. In general, this dynamic optimization problem is a matter of choosing a policy/control that will optimize a function of the objectives to be achieved. In choosing a policy/control, it should also be noted how the observed system changes in time. The rules that govern the system are usually written in a differential equation or a different equation 
depending on whether the system is formulated in a continuous or discrete form. In addition, it is also possible that some constraints limit policy/control variables, state variables or mixtures between the two variables. This makes the dynamic optimization problem very complex. Therefore, in addition to special cases such as linear or quadratic solution, analytic solutions to dynamic optimization problems are difficult to obtain. Thus, the numerical method becomes an important alternative method to solve the dynamic optimization problem.

\section{Theoretical Framework}

One important method in numerical methods that is related to constrained dynamic optimization problems is the penalty method. This method is widely used because it is very simple and easy to implement. Broadly speaking, this method works as follows: if at any time by choosing certain policies/controls the resulting system state violates the constraints then a penalty is given to the objective function. Conversely, if at any time with a certain policy/control the state of the system produced does not violate the constraints then no penalty is given to the objective function. Thus, for each time this method will choose a particular policy/control that results in a system state that does not violate the constraints. Penalties commonly given to solve dynamic optimization problems are linear as in [1]-[4]. This paper presents an alternative penalty method to solve constrained dynamic optimization problems by using penalties in the form of fractions that can be seen as an extension of linear form.

\section{Methodology}

The results of the research are literature review that is supported by numerical experimental results. The literature review is used to develop theories that provide assurance that the method developed will provide the correct solution. While numerical experiments through simulations are used to verify the proposed hypothesis. By comparing the results of the simulation with the previously-known solution, the accuracy level of the developed method can be seen. This experiment took some examples of problems with known analytical and numerical solutions.

\section{Discussion}

In this section, the basic theory of convergence using the fractional rank method in solving the dynamic optimization problem is constrained. This research is using the minimum principle of Pontrygin, which can be seen in [5], [6] and the results are tested with numerical examples that support the theory developed.

\subsection{Problem Formulation}

The problem discussed in this paper is a dynamic optimization problem with the state constraints described below. The objective function is minimized as the following:

$$
\min _{u \in \Gamma} I(u)=\int_{0}^{T_{f}} F(x, u, t) d t+\psi(x(T))
$$

On condition that the initial value problem:

$$
\begin{gathered}
\frac{d x}{d t}=f(x, u, t), \quad x \in \mathbb{R}^{n}, \quad \forall t \in\left(0, T_{f}\right] \\
x(0)=x_{0}, \quad x_{0} \in \mathbb{R}^{n}
\end{gathered}
$$


And state constraints:

$$
\Gamma=\left\{u \in \mathbb{R}^{m} \mid h(x, u, t) \leq 0\right\}, \quad \forall t \in\left(0, T_{f}\right] .
$$

In this problem, $x$ refers to state vector, $u$ refers to control vector, and $t$ refers to time. Constant $T_{f}>0$ refers to end time of observation. The functions $F: \mathbb{R}^{n+m+1} \rightarrow \mathbb{R}, \psi: \mathbb{R}^{n} \rightarrow \mathbb{R}, f: \mathbb{R}^{n+m+1} \rightarrow$ $\mathbb{R}^{n}$ and $h: \mathbb{R}^{n+m+1} \rightarrow \mathbb{R}^{p}$ are known and differentiated level two of all the arguments continuously.

The problem of dynamic optimization constrained above can be solved more easily if it is changed to a problem of dynamic optimization without constraints. The step commonly performed is to add constraints as a number called penalty number into the objective function. If at any time in a state and policy/control the constraints are met, the number of penalty equals to zero. Conversely, if the constraints are not met, the number will have great value, so it is against the goal to minimize the objective function. Thus, this method will choose policy/control which at a certain time results a state that meets the given constraints. In this case, the penalty number is to the power of the following fraction:

$$
\min _{u \in \Gamma} J(u, \theta)=I(u)+\int_{0}^{T_{f}} \theta^{T} h^{1 / s}(x, u, t) d t
$$

which must meet the initial value problem,

$$
\begin{gathered}
\frac{d x}{d t}=f(x, u, t), \quad x \in \mathbb{R}^{n}, \quad \forall t \in\left(0, T_{f}\right] \\
x(0)=x_{0}, \quad x_{0} \in \mathbb{R}^{n}
\end{gathered}
$$

The vector $\theta=\left(\theta_{1}, \theta_{2}, \ldots, \theta_{p}\right)^{T}$ is penalty factor which elements are the functions of time $t$ with values always greater than $0\left(\theta_{i}(t)>0, \forall i=1,2, \ldots, p, \forall t\right)$ for each time. The function valued vector $h^{1 / s}=\left(h_{1}^{1 / s}, h_{2}^{1 / s}, \ldots, h_{p}^{1 / s}\right)$ is defined as follows:

$$
h_{i}^{1 / s}(x, u, t)=\left\{\begin{array}{cc}
0, & \text { if } h_{i} \leq 0 \\
h_{i}^{1 / s}, & \text { if } 0<h_{i}<1 \\
h_{i}, & \text { if } h_{i} \geq 1
\end{array}\right.
$$

$\forall i=1,2, \ldots, p$. Whereas the constant $s$ is a member of a set of natural numbers.

The following is given a theorem which states that solving the constraints of dynamic optimization without constraints with the fractional rank penalty method will be the same as solving the dynamic optimization with constraints.

Theorem 1

For example $\left(x^{*}, u^{*}\right)$ is stationary point and $H$ is Hamiltonian function from dynamic optimization problems to constraint that is:

$$
H(x, u, t, \lambda)=F(x, u, t)+\lambda^{T} f(x, u, t)+\mu^{T} h(x, u, t) .
$$


For example $\psi_{x x}$ (semi) positive definite and $H_{u u}$ as well as $H_{x x}-H_{x u} H_{u u}^{-1} H_{u x}$ positive definite at $\left[0, T_{f}\right]$. If $\theta_{i}(t) \geq \mu_{i}(t), \forall i=1,2, \ldots, p$ then $u^{*}$ is a local solution of the dynamic optimization problem without the constraints above.

Proof:

For $s=1$, that is linear penalty case, the solution can be seen in (Xing, 1994). The solution will be broadened for case $s>1, s \in \mathbb{N}$ as follows.

For example, $u^{*}+\delta u$ with range of policy/control and $x^{*}+\delta x$ with $\delta x(0)=0$ is a state in accordance with the policy/control, so

$$
\Delta J\left(u^{*}, \theta\right)=I\left(u^{*}+\delta u\right)-I\left(u^{*}\right)+\int_{0}^{T_{f}} \theta^{T}\left(h^{\frac{1}{s}}\left(x^{*}+\delta x, u^{*}+\delta u, t\right)-h^{\frac{1}{s}}\left(x^{*}, u^{*}, t\right)\right) d t
$$

Because when the stationary point is $h\left(x^{*}, u^{*}, t\right)=0$ then $h^{1 / s}\left(x^{*}, u^{*}, t\right)=0$ so

$$
\begin{array}{rl}
\Delta J\left(u^{*}, \theta\right)=\int_{0}^{T_{f}} & H\left(x^{*}+\delta x, u^{*}+\delta u, t\right)-\lambda^{T} f\left(x^{*}+\delta x, u^{*}+\delta u, t\right) \\
& -\mu^{T} h\left(x^{*}+\delta x, u^{*}+\delta u, t\right) d t+\psi\left(x^{*}\left(T_{f}\right)+\delta x\left(T_{f}\right)\right) \\
& -\int_{0}^{T_{f}} H\left(x^{*}, u^{*}, t\right)-\lambda^{T} f\left(x^{*}, u^{*}, t\right) d t-\psi\left(x\left(T_{f}\right)\right)+\int_{0}^{T_{f}} \theta^{T} h^{1 / s}\left(x^{*}\right. \\
& \left.+\delta x, u^{*}+\delta u, t\right) d t
\end{array}
$$

By using Taylor series and Pontryagin minimum principle that $H_{u}\left(x^{*}, u^{*}, t\right)=0$, the last equation can be written as follows:

$$
\begin{aligned}
\Delta J\left(u^{*}, \theta\right)=\int_{0}^{T_{f}} & H_{x} \delta x+\frac{1}{2}\left(\delta x^{T} H_{x x} \delta x+2 \delta x^{T} H_{x u} \delta u+\delta u^{T} H_{u u} \delta u\right) d t-\int_{0}^{T_{f}} \lambda^{T} d(\delta x) \\
& -\mu^{T} h\left(x^{*}+\delta x, u^{*}+\delta u, t\right) d t+\psi\left(x^{*}\left(T_{f}\right)\right)^{T} \delta x\left(T_{f}\right) \\
& +\frac{1}{2} \delta x^{T}\left(T_{f}\right) \psi_{x x}\left(x^{*}\left(T_{f}\right)\right) \delta x\left(T_{f}\right)+\int_{0}^{T_{f}} \theta^{T} h^{\frac{1}{s}}\left(x^{*}+\delta x, u^{*}+\delta u, t\right) d t \\
& +S(\delta x, \delta u)
\end{aligned}
$$

With $S(\delta x, \delta u)$ is the remaining number proving that $|S(\delta x, \delta u)| \rightarrow 0$ jika $\|\delta x\| \rightarrow 0$ dan $\|\delta u\| \rightarrow 0$.

By partially making the number of the two equations integral and by using other Pontryagin minimum principle, which is $H_{x}\left(x^{*}, u^{*}, t\right)=-\frac{d}{d t} \lambda^{T}(t)$ and $\lambda\left(T_{f}\right)=\psi_{x}\left(x^{*}\left(T_{f}\right)\right)$, it is obtained 


$$
\begin{aligned}
\Delta J\left(u^{*}, \theta\right)=\int_{0}^{T_{f}} & \frac{1}{2}\left(\delta x^{T} H_{x x} \delta x+2 \delta x^{T} H_{x u} \delta u+\delta u^{T} H_{u u} \delta u\right) d t \\
& +\frac{1}{2} \delta x^{T}\left(T_{f}\right) \psi_{x x}\left(x^{*}\left(T_{f}\right)\right) \delta x\left(T_{f}\right)+\int_{0}^{T_{f}}\left(\theta^{T} h^{\frac{1}{s}}-\mu^{T} h\right)\left(x^{*}+\delta x, u^{*}\right. \\
& +\delta u, t) d t+S(\delta x, \delta u)
\end{aligned}
$$

If the theorem noted that $\theta_{i}(t) \geq \mu_{i}(t), \forall i=1,2, \ldots, p$ and also depend on the definition of $h_{i}^{1 / s}$ it can be concluded that $h_{i}^{1 / s} \geq h_{i}, \forall i=1,2, \ldots, p$ then

$$
\int_{0}^{T_{f}}\left(\theta^{T} h^{\frac{1}{s}}-\mu^{T} h\right)\left(x^{*}+\delta x, u^{*}+\delta u, t\right) d t \geq 0
$$

For example $\delta^{2} J=\int_{0}^{T_{f}} \frac{1}{2}\left(\delta x^{T} H_{x x} \delta x+2 \delta x^{T} H_{x u} \delta u+\delta u^{T} H_{u u} \delta u\right) d t+$ $\frac{1}{2} \delta x^{T}\left(T_{f}\right) \psi_{x x}\left(x^{*}\left(T_{f}\right)\right) \delta x\left(T_{f}\right)$ then obtained

$$
\Delta J\left(u^{*}, \theta\right) \geq \delta^{2} J+S(\delta x, \delta u) .
$$

Because in the theorem it is known that $H_{u u}$ and $H_{x x}-H_{x u} H_{u u}^{-1} H_{u x}$ is positive definite, it is possible to use $r>0$ (small enough) so $H_{u u}-r I$ positive definite and $\left(H_{x x}-r I\right)-H_{x u}\left(H_{u u}-\right.$ $r I)^{-1} H_{u x}$ is also positive definite. and

Thus, it is obtained the matrix $P$ in such a way that $P^{T} P=\left(H_{x x}-r I\right)-H_{x u}\left(H_{u u}-r I\right)^{-1} H_{u x}$

$$
\begin{aligned}
& \delta^{2} J \\
& -\frac{r}{2} \int_{0}^{T_{f}}\left(\delta x^{T} \delta x+\delta u^{T} \delta u\right) d t \\
& =\frac{1}{2} \delta x^{T}\left(T_{f}\right) \psi_{x x}\left(x^{*}\left(T_{f}\right)\right) \delta x\left(T_{f}\right) \\
& +\frac{1}{2} \int_{0}^{T_{f}}\left[\delta u+\left(\begin{array}{c}
\left.H_{u u}-r I\right)^{-1} H_{u x} \delta x \\
P \delta x
\end{array}\right]^{T}\left[\begin{array}{cc}
H_{u u}-r I & 0 \\
0 & I
\end{array}\right]\left[\begin{array}{c}
\delta u+\left(H_{u u}-r I\right)^{-1} H_{u x} \delta x \\
P \delta x
\end{array}\right] d t \geq 0\right.
\end{aligned}
$$

Therefore, it can be concluded that

$$
\Delta J\left(u^{*}, \theta\right) \geq \frac{r}{2} \int_{0}^{T_{f}}\left(\delta x^{T} \delta x+\delta u^{T} \delta u\right) d t+S(\delta x, \delta u) \geq 0
$$

for $\|\delta u\| \rightarrow 0$.

In other words, it is proven that $u^{*}(t)$ is the local solution from the optimization without any constraints above.

\section{Consequence 1}

Based on the same assumptions on the theorem, $u^{*}(t)$ is also a local solution to the problem of optimization with constraints. 
Proof:

Because of $u^{*}(t)$ is a local solution from the problem of optimization without obstacles then there is $\varepsilon>0$ so that $\Delta J\left(u^{*}, \theta\right) \geq 0$ for all $u(t) \in \mathrm{N}_{\varepsilon}\left(u^{*}(t)\right)$ with $\mathrm{N}_{\varepsilon}\left(u^{*}(t)\right)=\left\{u(t) \mid\left\|u(t)-u^{*}(t)\right\|<\varepsilon\right\}$. It is also applies for $\mathrm{N}_{\varepsilon}\left(u^{*}(t)\right) \cap \Gamma$. Thus,

$$
I\left(u^{*}\right)=J\left(u^{*}, \theta\right) \leq J(u, \theta)=I(u) .
$$

So, with the same assumptions as in the theorem, it is proven that $u^{*}(t)$ is also a local solution to the problem of optimization with constraints.

As aforementioned, the penalty number to the power of $h^{\frac{1}{s}}(x, u, t)$ is not differentiable when the value is 0 . Therefore, the standard optimization algorithm that involves derivatives cannot be used. Because of that, in the practice the number should be changed into the differentiable version as follows:

$$
h_{\tau}^{1 / s}=\left\{\begin{array}{cc}
0, & \text { if } h<-\tau \\
\left(\frac{3}{4}-\frac{1}{2 s}\right) \tau^{\left(\frac{1}{s}-2\right)}(h+\tau)^{2}+\left(\frac{1}{4 s}-\frac{1}{4}\right) \tau^{\left(\frac{1}{s}-3\right)}(h+\tau)^{3}, & \text { if }-\tau \leq h \leq \tau \\
h^{1 / s}, \quad \text { if } \tau<h<1 & \text { if } h \geq 1
\end{array}\right.
$$

With smoothing constant of $\tau>0$ (small enough). In this case, the undifferentiability $h_{\tau}^{1 / s}$ when the value is 1 it does not make any problem because what needs to be considered is the convergence $h_{\tau}^{1 / s}$ when the value is 0 , that is when the constraint is active.

\subsection{Numeric Simulation}

The theoretical results that have been described in the previous scheme, then is verified using numeric simulation. There are 2 samples that are used in the simulation. The software used in this simulation is MISER 3.3, a program for completing dynamic optimization/ optimal control constraints. The algorithm in MISER 3.3 is based on the parameterizatoin method of policy/control in [7]. For the sake of this study, some parts of the subprograms in MISER 3.3 need some modification. Further explanation about MISER 3.3 can be seen in [8].

Example $1[2]$,

$$
\min _{u} I=\int_{0}^{1} x^{2}+u^{2}-2 u d t+\frac{1}{2}(x(1))^{2}
$$

which must meet the initial value problem

$$
\frac{d x}{d t}=u, x(0)=0
$$

and the constraint

$$
h(x, u, t)=-\left(x^{2}+u^{2}-t^{2}-1\right) \leq 0 .
$$

The analytical solution for this problem is $x^{*}(t)=t$ and $u^{*}(t)=1$, so that the problem is always active for all time. The minimum objective function value is $-\frac{1}{6} \approx-0,166666 \ldots$

Besides that, analytically it is obtained 


$$
\lambda(t)=2-e^{\frac{\left(t^{2}-1\right)}{2}}, \quad \mu(t)=1-\frac{1}{2} e^{\frac{\left(t^{2}-1\right)}{2}}
$$

It can also be proven that $\psi_{x x}, H_{u u}$ and $H_{x x}-H_{x u} H_{u u}^{-1} H_{u x}$ is positive definite. So, all assumption in Theorem 1 is fulfilled. If $\theta(t) \geq \mu(t)$ for every time, the penalty method powered to a fraction with varied $s$ value with smoothing constant $(\tau=0,01)$ will converge to the analytic solution as shown in Table 1.

Table 1. Value of objective function for various value of $s$ and $\theta$

\begin{tabular}{ccc}
\hline $\mathbf{S}$ & $\boldsymbol{\theta}$ & $\mathbf{I}$ \\
\hline 2 & 1 & $-0,166601671$ \\
3 & 1 & $-0,166601409$ \\
4 & 5 & $-0,166601490$ \\
\hline
\end{tabular}

More specifically, for $s=2, \theta=1$ the more detailed simulation result can be seen in Table 2 . From Table 2, it is seen that the numeric result for state function and optimization policy/control show very small number of differences compared to state function and optimization policy/control obtained from the analytic solution.

Table 2. Value of policy/control and optimal state for $s=2, \theta=1$

\begin{tabular}{ccc}
\hline $\mathbf{t}$ & $\mathbf{u}(\mathbf{t})$ & $\mathbf{x}(\mathbf{t})$ \\
\hline 0,0 & 1,00006 & 0,00000 \\
0,1 & 1,00005 & 0,10001 \\
0,2 & 1,00005 & 0,20001 \\
0,3 & 1,00004 & 0,30002 \\
0,4 & 1,00004 & 0,40002 \\
0,5 & 1,00004 & 0,50002 \\
0,6 & 1,00003 & 0,60003 \\
0,7 & 1,00003 & 0,70003 \\
0,8 & 1,00002 & 0,80003 \\
0,9 & 1,00002 & 0,90004 \\
1,0 & 1,00002 & 1,00004 \\
\hline
\end{tabular}

Figure 1 shows the function graph and optimal policy/control to time. It is seen that the result of numeric simulation is very close to the analytic solution.

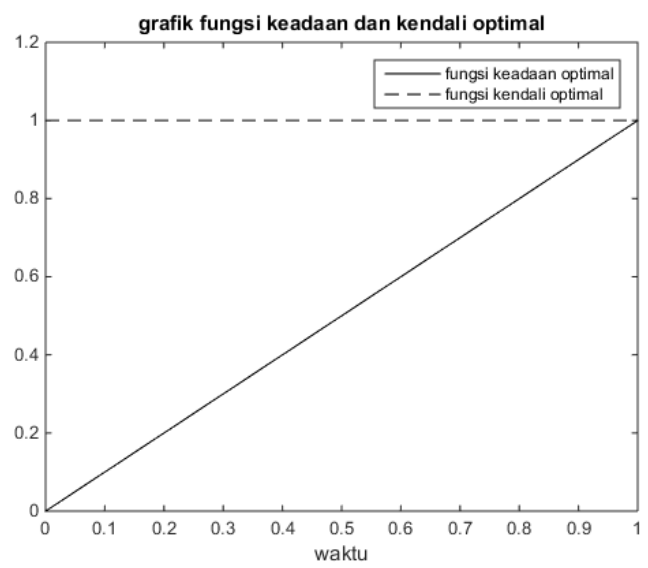

Figure 1. Graph of state function and optimal control 
For example

The problem is taken from [7] as follows

$$
\min _{u} I=\int_{0}^{1} x_{1}^{2}+x_{2}^{2}+0,005 u^{2} d t
$$

That should meet the initial value

$$
\begin{gathered}
\frac{d x_{1}}{d t}=x_{2}, \quad x_{1}(0)=0 \\
\frac{d x_{2}}{d t}=-x_{2}+u, x_{2}(0)=-1
\end{gathered}
$$

And the constraint

$$
g(x, t)=-8(t-0,5)^{2}+0,5+x_{2} \leq 0 .
$$

The analytic solution for this constrain is difficult to obtain so the best numeric solution is used as in [8] which objective function is 0,1736 as comparison to the result of numeric simulation that has been performed.

Because the constraint of this problem does not involve variable of policy/control, so the constraint needs to be changed into:

$$
h(x, u, t)=0,9 g(t, x)+0,1 g^{\prime}(t, x) .
$$

with

$$
g^{\prime}(t, x)=\frac{d g}{d t}=\frac{\partial g}{\partial x} \frac{d x}{d t}+\frac{\partial g}{\partial t}
$$

The result of the constraint numeric simulation for various value of $s$ with smoothing constant is shown in Table 3.

Table 3. Value of objective function for various value of $s$ and $\theta$

\begin{tabular}{ccc}
\hline $\mathbf{s}$ & $\boldsymbol{\theta}$ & $\mathbf{I}$ \\
\hline 2 & 10 & 0,181512014 \\
3 & 1 & 0,181487693 \\
4 & 1 & 0,181524537 \\
5 & 1 & 0,181860645 \\
\hline
\end{tabular}

Figure 3 shows that the difference between the values that is obtained through numerical simulations performed does not differ greatly compared to the values obtained from [7] that is less than 0,01 .

More specifically, for $s=3, \theta=1$, the detailed numerical simulation results are given in Table 4. Figures 2, 3, and 4 illustrate optimal control functions and optimal state functions obtained from simulation results consecutively. The similar pictures with the simulation results used as comparison can be seen in [7]. 
Table 4. Value of policy/control function and optimal state for $s=3, \theta=1$

\begin{tabular}{cccc}
\hline $\mathbf{t}$ & $\mathbf{u}(\mathbf{t})$ & $\mathbf{x}_{\mathbf{1}}(\mathbf{t})$ & $\mathbf{x}_{\mathbf{2}}(\mathbf{t})$ \\
\hline 0,0 & 8,33795 & 0,00000 & $-1,00000$ \\
0,1 & 1,29066 & $-0,05483$ & $-0,11138$ \\
0,2 & $-2,25201$ & $-0,05918$ & 0,02204 \\
0,3 & $-2,77413$ & $-0,06798$ & $-0,19436$ \\
0,4 & $-1,26570$ & $-0,09990$ & $-0,43986$ \\
0,5 & 0,26720 & $-0,14788$ & $-0,51846$ \\
0,6 & 2,08561 & $-0,19592$ & $-0,44368$ \\
0,7 & 1,86028 & $-0,22805$ & $-0,20299$ \\
0,8 & 0,21192 & $-0,23837$ & $-0,00664$ \\
0,9 & $-0,05963$ & $-0,23798$ & 0,01416 \\
1,0 & $-0,05963$ & $-0,23692$ & 0,00713 \\
\hline
\end{tabular}

Figure 4 describe, at any point of time, the graph of state variable functions $x_{2}$ is always below the quadratic function graph of $8(t-0,5)^{2}-0,5$. Thus, for each time the obstacle is always met by the optimal solution obtained because $-8(t-0,5)^{2}+0,5+x_{2} \leq 0$.

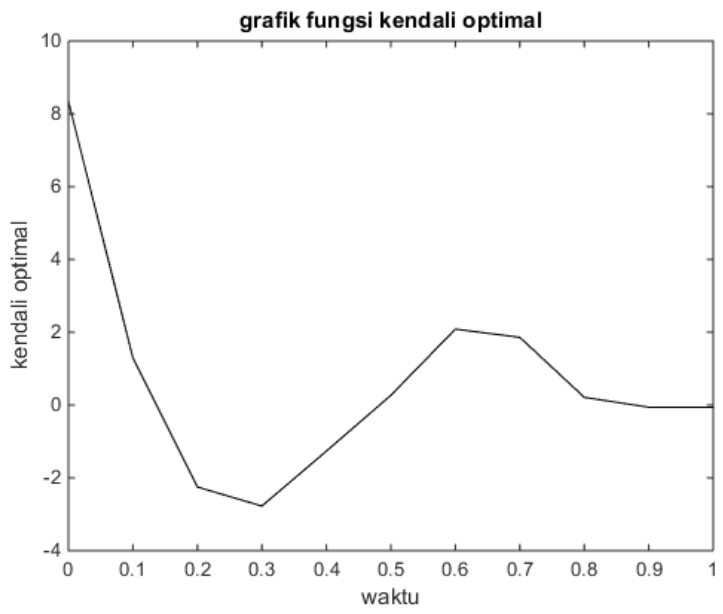

Figure 2. Graph of optimal control functions

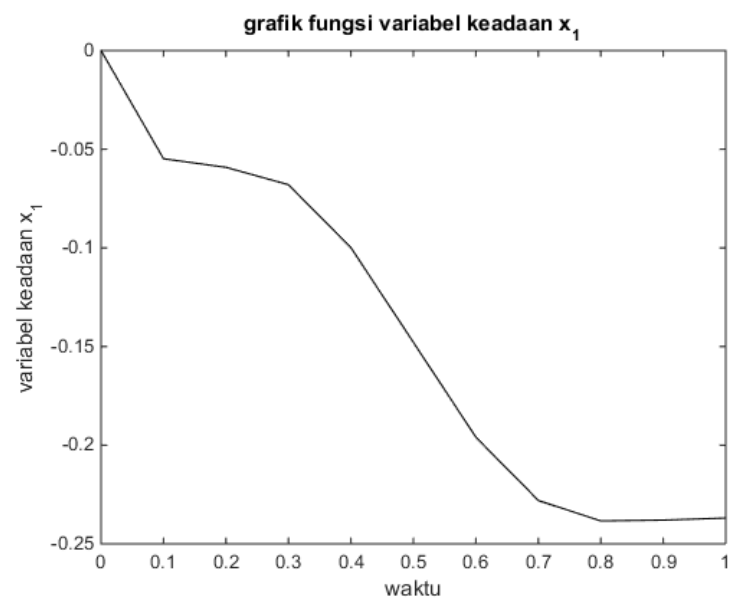

Figure 3. Graph of state variable functions $x_{1}$ 


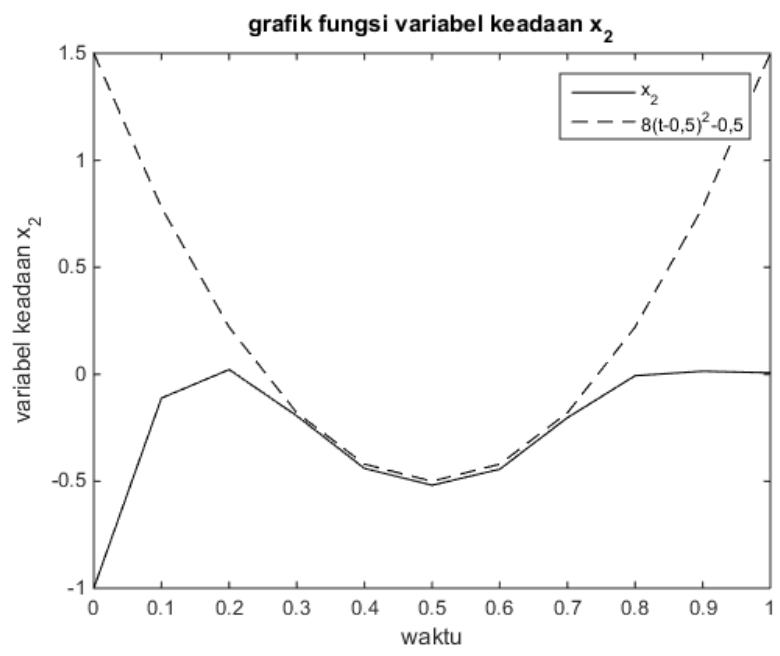

Figure 4. Graph of state variable functions $x_{2}$

\section{Conclusion}

The conclusion of this research is theoretically the fractional rank penalty method can be used to solve dynamic optimization problems constrained by circumstances. This result is reinforced by the results of numerical simulations which show the settlement of using the fractional rank accuracy method does not differ much with the analytical solution or comparative settlement obtained by other methods. Thus, the fractional rank penalty method is effective to be used as an alternative method in solving dynamic optimization problems constrained by circumstances.

\section{References}

[1] J. A. Snyman, C. Frangos, and Y. Yavin, "Penalty function solutions to optimal control problems with general constraints via a dynamic optimisation method," Comput. Math. with Appl., 1992.

[2] A. . Xing, "The Exact Penalty Function Method in Constrained Optimal Control Problems," $J$. Math. Anal. Appl., 1994.

[3] Q. H.Y, "A Penalty Method for Solving Inequality Path Constrained Optimal Control Problems," Acta Autom. Sin., 2013.

[4] P. Malisani, F. Chaplais, and N. Petit, "An interior penalty method for optimal control problems with state and input constraints of nonlinear systems," Optim. Control Appl. Methods, 2016.

[5] J. L. Speyer and D. H. Jacobson, Primer on Optimal Control Theory. 2010.

[6] M. I. Kamien, Dynamic Optimization: The Calculus of Variations and Optimal Control in Economic and Management, 2nd ed. New York: Dover, 2013.

[7] C. J. Goh and K. L. Teo, "Control parametrization: A unified approach to optimal control problems with general constraints," Automatica, 1988.

[8] L. S. Jennings, MISER 3 Optimal Control Software: Theory and User Manual version 3. Perth: Department of Mathematics, University of Western Australia, 2004. 